\title{
Decentralized biotechnologies in production-use networks of biological control agents
}

\section{Mini review}

The territorialization of food systems constitutes a recent strategy for the production and consumption of food, which fosters local sovereignty in obtaining and using appropriate bio-inputs to their socioeconomic characteristics, including entomophagous, entomonematodes, and microbiological biopesticides.

The massive and decentralized multiplication of biological control agents is traditional in Cuban agriculture; the first studies and practical applications began in the middle of the last century in the sugar cane cultivation and continued during the 70-80s with the rest of agriculture, with a reinforcement since the $90 \mathrm{~s},{ }^{1}$ benefiting annually 2.4 million hectares with bioproducts obtained in a network of 175 laboratories known as CREE (Center for the Reproduction of Entomophagues and Entomopathogens) and four Biopesticide Plants. ${ }^{2}$

These units are located in agricultural territories and are managed by the farmers' organizations themselves, an experience that originated in the 1940s in the old laboratories for the artisanal multiplication of Lixophaga diatraeae, a very effective parasitoid in the biological control of the sugar cane borer; which was subsequently continued in the CREE model and is considered a very valuable strategy for the adoption of biological control by farmers and contributes to the sustainability of this technology. ${ }^{3}$

The biological control program has been consolidated as a system that includes research, production, quality control, use and determination of technical efficiency, which has been integrated into agricultural territories in three main action levels: (a) mass production by the CREE and Biopesticide Plants, which receive technological support from the Provincial Plant Health Laboratories (advice, supply of ecotypes and strains, quality control); (b) local management by the Territorial Plant Protection Stations (ETPP); (c) integration into the management of the crop, by the phytosanitary technicians of the productive forms, together with the farmers. ${ }^{4}$

This massive development of biological control in Cuban agricultural production has been sustained by a system that has favored incremental innovation, ${ }^{3}$ mainly since the mid-1990s, facilitated by the network of laboratories and stations of the plant health service, in conjunction with farmers, which have led to greater integration of biological control and pest management to the crop production system and the agricultural territory.

During more than 70 years of biological control in the agroecosystems of $\mathrm{Cuba}$, it has been shown that, in conventional production systems, where synthetic pesticides are also used, biological control agents are used with increasing criteria and inputs substitution, which is why they need to be applied at different times. On the other hand, with the rise of agroecology since the end of the 1990s, in production systems in agroecological transition, the functions of ecological self-regulation are increased, where a quality habitat is provided for its regulatory activity and establishment, as well as synergies between these and the natural enemies that inhabit agroecosystems.
Volume 8 Issue 2 - 202I

\author{
Luis LVazquez \\ Cuban Association of Agricultural and Forestry Technicians, \\ Cuba \\ Correspondence: Luis LVazquez, Cuban Association of \\ Agricultural and Forestry Technicians (ACTAF). Havana. Cuba, \\ Email Ilvazquezmoreno@yahoo.es
}

Received: March 09, 2021 | Published: April 27, 2021

Precisely, the strategy for the conservation of natural enemies includes practices that protect, favor the development, and manage these organisms in the agroecosystem, be they parasitoids, predators, parasites, or pathogens, to increase the regulatory activity of the most efficient species or achieve greater regulation rates as a result of the joint action of the different species that cohabit, including biological control agents that are released or applied in augmentation programs. ${ }^{5}$

The latter is particularly possible because most of the available technologies, which are based on industrial, semi-industrial, and artisanal processes, obtain bio products in which the biological control agent is present in its infective stage; this is why the greatest success and sustainability in biological control programs is achieved when the productions are carried out in the agricultural territories themselves, using native species, strains, and ecotypes or of proven efficacy under local conditions.

Unlike commercial bio products that are offered as technological packages, these biotechnologies are appropriate because the production process and the utilization system are decentralized at the scale of the territories, where collaboration networks between biotechnologists and farmers are facilitated, which contribute to understanding and achieve a quality habitat for the application or release of these organisms.

\section{Acknowledgments}

None.

\section{Conflicts of interest}

Authors declare that there is no conflict of interest.

\section{Funding}

None.

\section{References}

1. Pérez N, Vázquez LL. Ecological pest management. In: Transforming the Cuban countryside. Avances de la Agricultura Sostenible. 2001;191-223. 
2. Márquez ME, Vázquez LL, Rodríguez MG, et al. Biological control in Cuba. In:Van Lenteren JC, Bueno VHP, Luna MG, editors. Biological control in Latin American and the Caribbean. Its rich history and bright future. CABI Invasive series. 2020;176-193.

3. Vázquez LL, Chia, E. Innovation and auto-governing territorial control of biology in Cuba. Agroecología. 2020;14:69-79.
4. Vázquez LL, Pérez N. The integrated biological control of the territorial range of insect plagues in Cuba. Agroecology. 2017;12(1):39-46.

5. Matienzo Y, Vázquez LLL, Alfonso-Simonetti J. Quality of Agro ecosystems as Habitats to Natural Enemies and Biological Control Agents.. In: Souza B, Vázquez LL, Marucci RC, editors. Natural Enemies of Insect Pests in Neotropical Agroecosystems. Biological Control and Functional Biodiversity. Springer Nature Switzerland AG; 2019;3:27-34. 